\title{
The Use of Contestation and Social Norms in Developing Radicalized Discourses Online
}

\author{
Rachel Lara Davis \\ West Virginia University
}

Follow this and additional works at: https://researchrepository.wvu.edu/etd

\section{Recommended Citation}

Davis, Rachel Lara, "The Use of Contestation and Social Norms in Developing Radicalized Discourses Online" (2011). Graduate Theses, Dissertations, and Problem Reports. 3311.

https://researchrepository.wvu.edu/etd/3311

This Thesis is protected by copyright and/or related rights. It has been brought to you by the The Research Repository @ WVU with permission from the rights-holder(s). You are free to use this Thesis in any way that is permitted by the copyright and related rights legislation that applies to your use. For other uses you must obtain permission from the rights-holder(s) directly, unless additional rights are indicated by a Creative Commons license in the record and/ or on the work itself. This Thesis has been accepted for inclusion in WVU Graduate Theses, Dissertations, and Problem Reports collection by an authorized administrator of The Research Repository @ WVU. For more information, please contact researchrepository@mail.wvu.edu. 
The Use of Contestation and Social Norms in

\title{
Developing Radicalized Discourses Online
}

\author{
Rachel Lara Davis \\ Thesis submitted to the \\ Perley Isaac Reed School of Journalism \\ at West Virginia University \\ in partial fulfillment of the requirements for the degree of \\ Master of Science \\ in \\ Journalism
}

Bob Britten, Ph.D, Chair

Rita Colistra, Ph. D

Jessica Troilo, Ph. D

Steve Urbanski, Ph. D

Perley Isaac Reed School of Journalism

Morgantown, West Virginia

2011

Keywords: Commenting, Blogging, Public Sphere, Radicalized Public Sphere, Online Discourse, Comment Threads

Copyright 2011 Rachel Lara Davis 


\section{ABSTRACT \\ The Use of Contestation and Social Norms in Developing Radicalized Discourses Online}

\section{Rachel Lara Davis}

This thesis investigated how discourses developed in blog's comment threads work to promote the development of a radicalized public sphere. Using Dahlberg's (2007) concept of radicalized public sphere as an alternative to the mainstream, largely media-controlled, Habermasian public sphere, this study investigated how comments from treehugger.com and techcrunch.com worked to promote or inhibit radicalized public sphere development through the use of discursive radicalism and inter-discursive contestation. Ideological criticism, in combination with the constant comparative method, was employed to code each comment and develop a system of identification for each type of comment based on the ideology it presented, and the rhetorical strategy used to convey its ideology. Coded comments were grouped into categories, and those categories grouped into broader categories, until a dominant form of commenting was identified.

The results from this study showed that discourse-promoting comments, which met the definition of discursive radicalism provided by Dahlberg (2007), dominated the comments on both blogs. Furthermore, it was found that normalizing comments were present on the comment threads, but did not dominate the discourse. These results suggest that radicalized public sphere discourse is functioning in the comment threads of the blogs in this investigation. Further studies are necessary, however, to gain a better understanding of the nature of commenting and the development of a radicalized public sphere on the numerous and diverse blog sites that populate the Internet. 


\section{Introduction}

This thesis investigated how forms of social control occurring in blog comments influence blog users' ability to develop counter public spheres through discursive radicalism. The emergence of blogs as a popular means of communication and as an alternative to mainstream publications for news and other information, makes them an ideal means through which to develop online public sphere formations. With the ever-increasing popularity of blogs, "there are now greatly increased possibilities for ordinary (and extraordinary) people to express themselves and/or their opinions online" (Gripsrud, 2009, p. 11). These possibilities also lead to the development of online communities. Individuals are now able, through online search engines, to find the sites and the blogs that appeal to their interests and read or discuss posts with other like-minded individuals.

With the potential to find news and material related to individual interests, however, comes greater potential for filtering. As Trenz (2009) claims, "Never has it been easier for the citizens to opt for those news outlets that reflect their values and political affiliations and to filter out all news and opinions that do not immediately confirm their worldview" (p. 44). With the link between media consumption and community development that blogs provide, the blog users' ability to filter their news also allows them to involve themselves in only the communities that suit their interests and represent their idea of how people should behave, write, interact, or think (Festinger, Riecken \& Schachter, 1956). In these types of communities, social controls have the potential to support and enforce the agreed upon ideologies (Noelle-Neumann, 1977; Sebler \& Johnson-Eliola, 1996). These social controls, in addition to the norms they enforce, work to exclude individuals with deviant ideas or opinions from entering the discourse (Sebler, Johnson-Eliola, 1996). Comment threads are designed to incorporate the ideas and perspectives 
of all users who visit the site, but with the influence of inclusive community development and the community's social norms, outside users may not be welcomed into established communities of blog users.

Dahlberg (2007) describes the radicalized public sphere as a network of dominant and counter-public spheres, which challenge each other through the development of divergent, public discourses. If blog comments use social controls as a tool for community norm enforcement, the contestation necessary for the development of a radicalized public sphere would be limited. By identifying the types of social controls and discourses that are occurring on blog comment threads and investigating which types of comments are using social controls promote or detract from the development of community norms, a better understanding of how open, radicalized democratic discourses can be developed on blogs and their comment threads may be achieved. Furthermore, pursuing this research will add to the available literature about blogs and the online commenting phenomenon, which tests Dahlberg's (2007) claim that blogs can be locales for radicalized democratic discourse development. Understanding how the practical matter of commenting on blogs relates to the theory on blog communication is essential both in testing the Dahlberg's online radicalized public sphere theory and in understanding the influence comments have on social developments online.

\section{Literature Review}

The mass media in the United States has been criticized as being biased toward various political, corporate, and private agendas (Beers, 2006; Robinson, 2006). This trend becomes problematic when the influence of the mass news media and the journalists producing the articles and reports that fuel it is taken into account. Robinson (2006) notes that:

Journalists must abide by a code to be objective, independent, accurate, and truthful. They have a responsibility to society to provide significant, relevant information that can 
be used to inform democracy. Through these standards, journalists end up setting the agenda for social debate (p. 65).

The code Robinson proposes suggests that journalists, through the information they produce and publish in the mass media, have the ability to guide the thinking of their audiences, at least to the extent of shaping their audiences' impressions of politics and their democratic decision-making processes (Gamson, Croteau, Hoynes \& Sasson, 1992; McCombs \& Shaw, 1972; Scheufele \& Tewksbury, 2007). In the traditional media system, journalists serve as, among other things, the gatekeepers of information and use their positions to frame the news they report on and control its distribution to the public (Shoemaker \& Reese, 1996; Maratea, 2008). This may allow journalists and the news organizations they write for to use agenda-setting strategies to promote only the topics they want the public to know about. Maratea (2008) explained that the way news stories are framed by the traditional media "not only affect[s] the news content, but also shape[s] the public's perceptions of issues, affect[s] the relative importance people attach to social problems, and is a powerful influence over both public and political agendas" (p. 141). With such system in place, it is difficult for individuals to gather adequate information to form their own opinions about important public issues.

This problem is further complicated by the media's use of a one-way, top-down form of information dissemination. In this system, professional journalists speak "as one to many" (Beers, 2006, p. 119), releasing news stories to the public for consumption but rarely receiving or accepting any feedback or criticism from the publics they inform. This system leaves the majority of individuals with very little influence on the media they consume and has forced them to rely on information that has been filtered through the traditional media (Maratea, 2008). Because of this public opinion generally reflects the opinion of the media, rather than the opinion of the public (Maratea, 2008). 


\section{Blogs as Online Discourse}

One proposed solution to the issues created by traditional media lies in online communication and its ability to form networks of interconnected users, each capable of publishing their own opinion and susceptible to criticism from any other Internet user (Farrell \& Drezner, 2008). Many communications tools available online, including e-mail, forums or message boards, and search engines, play a role in providing Internet users easy access to more diverse sources of information (Maratea, 2008). For this reason, many theorists hail the Internet as the great equalizer of the public (Al-Saggaf, 2006; Beers, 2006; Carroli, 1997; Dahlberg, 2007; Gripsrud, 2009). One important communication tool, the blog, has provided millions of people with the opportunity to post their thoughts and opinions online.

The introduction and increasing popularity of blogs has allowed Internet users to quickly and easily express themselves and their ideas in an online setting (Farrell \& Drezner, 2008; Gripsrud, 2009; Maratea, 2008). In this way, the Internet has "lowered the threshold for new entrants into the realm of cultural production in different media" (Gripsrud, 2009, p. 10) and has given Internet users the tools to become "authors of media content rather than a passive audience" (Al-Saggaf, 2006, p. 312). These possibilities for improved expression lead to possibilities for improved discourse. Citizens are now able to post information about themselves and review information about others that may lead to a greater understanding of differences in all aspects of life. In the traditional forms of news production, "consensus denies difference" (Carroli, 1997, p. 359). The denial of difference is manifested in the one-way, top-down transaction between news producer and news consumer. However, the emergence of the Internet "as a space of diversity and fragmentation rather than normative, unitary social formation" (p. 359) works to promote a diversity of opinions and ideologies that are readily available to the 
public and made by the public. In this way, individuals can work to question the information presented by the media and to promote their own interests, which may have been limited or excluded by the mass media.

As a reaction to the mass media's control over news production, online publications, such as blogs, have integrated news production and public discussion. Cammaerts (2008) states that: A blog can be defined as on online diary allowing the author(s) to share his/her/their views on a variety of subjects directed at a potentially global, but more often local or micro-publics, while at the same time also implicating its audience into responding and interacting with the content produced by the blogger (p. 358).

Online news blogs, which vary in content from stories copied from mainstream news sites to a plethora of more specific topics, including technology, arts, entertainment, and news related to minority groups, have emerged as the alternative way for modern audiences to get the information they are interested in and participate in a discussion about that information with users from around the world. There is an apparent increase, especially on news blogs, in the public's interest in the inner workings of government, business, and the media, which marks "an important shift towards deliberative democracy" (Collingwood, 2007, p. 15).

In developing her conceptualization of the possibilities of the Internet, Carroli (1997) backs Gripsrud's claim by suggesting that the Internet:

Has come to signify an intimate relationship between the local and the global that heralds the dispersal of established cultural institutions and the proliferation of diversity, and it provides a space in which new relations are both necessary and formative of new social networks (p. 359). 
Taking this into account, the Internet can be seen as beneficial to both the dissemination of information and the improvement of cultural understanding, to the point that "relational sets of opposition (are) also opened for interrogation" (p. 359). The cultural binaries of identity based on the concept of self vs. other generated by a lack of understanding, through the dispersal of information and the formation of counter-publics, are therefore presented online as something to question, discuss, or contest as much as important news stories or political policy. It is in this way that the Internet functions "as a space of diversity and fragmentation rather than normative, unitary social formation" (p. 359). By developing a form of democratic discourse, the users also engage in an online collaboration, which promotes diversity of information and discourses without requiring any consensus among the individuals participating in the discussion (Carroli, 1997).

The new approach to information consumption provided by blogs and comment threads also allows for ordinary people to become involved in the media they consume. Gripsrud (2009) claims that, with the increase of blogs available for public viewing and discussion, "there are now greatly increased possibilities for ordinary (and extraordinary) people to express themselves and/or their opinions online" (p. 11). Individuals can now go online, create their own blog site (in most cases for free) and start posting their ideas for the world to see (Farrell \& Drezner, 2008). This provides users the ability to discuss information important to them in a public forum, but also improves the diversity of content available on blogs. In contrast to the traditional forms of media, blogs and other online communications media are able to "multiply until every participant's concerns can find a space for discussion" (Sebler \& Johnson, 2006, p. 284). In doing so, blogs and comment threads provide, "a space of diversity and fragmentation rather than 
normative, unitary social formation," (Carroli, p. 359) which works to promote a diversity of opinions and ideologies that are readily available to the public and made by the public.

While many online blogging sites, including wordpress.com, blogger.com, and livejournal.com, make it possible for any Internet user to set up their own blog and begin posting material, not all blogs receive equal attention or representation online. The saliency of a blog, and the blogger's perspective that accompanies it, relies on the number of times that blog is linked to by other sites, and the number of page views the blog receives. The system of linking between blog sites allows for the spread of information, and readership, to occur more easily. The number of links leading to any blog, however, is skewed drastically in favor of the select few large, mainstream blogs (Ferrell \& Drezner, 2008). The centralization of links on a few large blogs allows outside users to easily find the information that interests them, but it may also lead readers to "concentrate their attention on a relatively small number of well-known blogs" (Maratea, 2008, p. 140). To ensure that a diversity of opinions are represented on these major blog sites, users may use the comment space that follows most blog posts to include their perspective on a topic without having to gain the attention and the links from a mainstream blog.

\section{Comments}

When investigating online discourses, it is important to consider the secondary discourses that are created by something like a blog post. Most research on online discourse looks only at the blogs themselves and their potential as a medium that allows any Internet user to publish their own ideas or opinions (Al-Saggaf, 2007; Beers, 2006; Dahlberg, 2007). Little attention is given to the discourses that occur on posts as responses to individual blog posts. Blogs, as a form of communication, allow for the development of discourses from their readers through the use of comment threads, which typically accompany every blog post (Beers, 2006). Comment threads 
serve as a way to allow users to incorporate their ideas or opinions on a blog post into the overall discourse on the blog. These threads are a unique feature that differentiates blogs from other more traditional forms of media that do not permit this degree of audience participation (Beers, 2006). Whereas blog posts are limited to publication on the author's blog site and are usually expected to be lengthier, a comment on a blog post can be as short or long as its author would like, and it appears on the same page as the blog it is responding to. Subsequent comments from other users may work as additional responses to the blog post or as responses to other comments. In this way, a discourse about a topic occurs in the space of one Internet page (or multiple linked pages, if the topic attracts a considerable amount of attention) where multiple perspectives can be represented and discussed.

Despite the lack of research focused on commenting that occurs on blogs, it is possible to infer some of the attributes and potentials of this form of discourse by comparing blog comments to research conducted on online forum use. According to Mann and Stewart (2000), a forum is "an online public discussion area where users exchange ideas and information. [It] usually has themes and topics and is controlled by a facilitator. Forum participants generally do not have to be online at the same time" (p. 219). Blog comments meet many of the same criteria as forums. Additionally, both forum posts and blog comments can be made anonymously (Witschge, 2008). More recently, some blogs commenters have been required to create accounts on the sites they are using before they are able to post a comment. Forums are typically moderated for inappropriate use, while moderation on comment threads is controlled by the blog author and is typically an optional setting when the author is creating his or her blog.

The similarities between forums and blog comments becomes more important in light of the claim that "web forums are often considered to be the 'genuine' public sphere: they allow 
many-to-many interactions, and relative to other media constituting part of the public sphere, there are few restrictions in accessing this space" (Witschge, 2008, p. 81). If blog comments are similar to forums, it is likely that commenting on blogs may also function as a genuine form of public sphere discourse.

Witschge's claim is challenged by other researchers' criticisms of blogging as “indulgent chatter of little interest to anyone but the blogger" (Nardi, Schiano, Gumbrecht, \& Swarts, 2004, p. 44) or as "a propaganda instrument, a marketing tool, and a distribution channel" (Cammaerts, 2008, p. 358). Such criticisms point to the major flaws of blogging as a form of online communication. With personal blogs, it is possible for the author to write only about their perspective or things that are of interest to him or her (Beers, 2006, p. 10). The result can be a small or non-existent readership for that blog, which suggests that that author's perspective is not reaching the public and is therefore not being integrated into the public's discourse. On larger blogs with regular readerships, it is possible for the author(s) to use their blogs to promote items in exchange for financial backing, or to host ads on their site and publish materials that will attract readers and make their site more valuable in the eyes of their advertisers (Barlow, 2008). This type of blog use leads to the same issues that currently plague the mainstream media, namely bias and interest in profit. Unlike blogs, comments to blog posts, when left unmoderated, may allow for the development of discourses based around the public's responses to the subject being presented in a blog. Comments have the potential to work as a check against bad reporting on blogs, because users are able to post links or information about problems or inaccuracies that appear in the blog post. They also have the potential to work as a place for discussion, where ideas from the post can be discussed, re-interpreted, or argued against in open conversation with other commenters and the blog's author. Because of this, commenting, like 
online forums, may be an ideal locale for the development of online public sphere discourses (Witschge, 2008).

\section{Guiding Theory}

\section{The Public Sphere}

In order to understand the concept of a radicalized public sphere and how it operates, it is important to first comprehend how the public sphere was originally thought to function. Habermas (1974) defines the public sphere as:

An entity that comes into being in every conversation in which private individuals assemble to form a public body. They then behave neither like business or professional people transacting private affairs, nor like members of a constitutional order subject to the legal constraints of a state bureaucracy (p. 49).

Habermas (1991) also describes the public sphere as, "the space of private people coming together as a public" where individuals can engage public authorities "in a debate over the general rules governing relations in the basically privatized but publicly relevant sphere of commodity exchange and social labor" (p. 27). Most important in this definition is the focus on private citizens as the source for deliberation. If journalists and news media are included in the public sphere, as they are in its modern conception, their behavior as "business or professional people" would lead to a biased discussion which supports the media outlets they work for and their personal and professional interests in those organizations' success. In the Habermasian public sphere, it is essential that individuals come to the discussion as a public form of a private citizen. As private citizens, individuals develop personal interests and biases. When they enter into the public sphere, it is necessary for citizens to bring their personal biases into the public 
conversation. This gives individuals' ideas representation in public discourse, and also allows others to consider these perspectives as valid without the threat of personal loss.

Habermas envisioned a weak form of the public sphere in Western democratic societies, which would allow citizens to "participate only up to the point where policy decisions are cut off inside the machinery of the political-administrative process" (Collingwood, 2007. p. 15). Politicians or individuals with influence on policy decisions within the government would not be included in this kind of public sphere but could be subject to the opinions presented in it. Citizens would be able to reach consensus on issues of public importance (p. 17), but the regulation of such issues would remain in the hands of political officials. Habermas' public sphere would operate like a town hall meeting, where issues that concern the community are presented and discussed among local citizens, businessmen, and politicians until the community's opinion is determined. All community members are able to present their opinion, but action on the issues discussed is reserved for the town's government to work on at a later time.

In the modern public sphere, however, there are several points where Habermas's conception falls short (see Figure 1). The Habermasian public sphere is complicated by the influence of the media on public discourse. Framing complicates public discourse by shaping the way individuals understand important events through the way it is presented in the mass media (Scheufele, 1999). Thus, the mass media's framing of information generates “a dominant framework of reportage shaping the news that reinforces the politico-economic dominant social order" (Robinson, 2006, p. 66). Beers (2006) uses the problematic gatekeeping nature of the mass news media, in which they have the power to control and shape the information being released to the public, as evidence for the necessity of independent, online news sources. He 
suggests that, "instead of allowing a sphere for debate that could shape the direction of the state, the increasingly commodified media became a force for manipulating the public and manufacturing consent" (p. 110). The solution to the mass media's control over public opinion, according to Beers, lies in the independent forms of media provided by the Internet.

Because the Internet provides news sources that are global, inexpensive, and easy to access, it is an ideal locale for the public sphere (Beers, 2006). Blogs especially, according to Beers, are integral in developing independent online media, because they are "forums where anyone can post stories or pictures or discuss what others have posted; thus the bias is not located in any conscious editorial decision-making authority" (p. 115). Blogs, therefore provide users exposure to information and perspectives beyond those available from the mass media. Many blogs today do rely on staff editors or individual owners to control what is published on their site, much like the traditional media: however, individuals may still create their own blog sites by either purchasing their own domain to host their page, or by using any of the numerous blog hosting sites that provide space online and blogging software for free when a user signs up. Individuals may also post comments on those mainstream blog sites as a way to insert their perspective into the overall conversation. By incorporating opinion as well as news and facts into a blog post and then allowing users to comment on either the opinion or the information provided, bloggers and users can gain a better understanding of other opinions through shared discourse. Blog users may also find discussions that inform them, are interesting to them, or display values similar to their own. In this way, citizens are given the ability to "intervene in the flow of events to either head off injustice or create a more just society" (p. 119) via the online discursive spaces provided by blogs.

\section{The Radicalized Public Sphere}


In addition to the power of the mainstream media over public sphere discourse, Dahlberg (2007) points to the "domination of politics by private power: the shaping of individual desires (through political or market publicity) or community norms (by invoking tradition, religion, patriarchal values, etc) by powerful interests" (p. 49) as the source of failure in the Habermasian public sphere. In contrast to Habermas's public sphere, Dahlberg's (2007) radicalized public sphere accounts for the influence of the mass media and private interest Dahlberg proposes a public sphere where contestation from participants works to counter these effects and challenge dominant discourses present in the media and in the majority of public sphere discourse.

According to Dahlberg (2007), the radicalized public sphere is a place in which members of a public, through their discourses, develop "debate and criticism that strengthens and develops oppositional discourses (identities, interpretations, social imaginaries and languages) to those dominating the mainstream public sphere" (p. 56). He suggests that "the Internet is conceived as a site and means of political struggle and conflict: a contested terrain where exclusion and domination as well as solidarity and resistance are reproduced" (p. 56). Unlike Habermas' conception of the public sphere, in which there is one sphere where discussion may take place and there is a single dominant discourse, Dahlberg's radicalized public sphere allows for multiple spheres of discourse. Termed counter public spheres, each constantly challenges the others for power and therefore constantly shift the hierarchized order of dominance is constantly shifting. The comparison here establishes the traditional media as the source and locale of the Habermasian public sphere, and suggests blogs as a potential source for the development of counter publics because of their ability to represent the seemingly endless array of minority interests. 
Dahlberg (2007) uses two concepts, discursive radicalism and inter-discursive contestation, to further explain the development of counter publics (see Figure 2). The first, discursive radicalism, is "a systematic antagonism blocking the suturing of meaning, including the defining of 'legitimate' public sphere boundaries" (p. 55). In comment threads this may be any case where a comment works to challenge an idea of the user community, whether it is one presented in a blog post, in another comment, or even a generally recognized norm. Dahlberg's second concept addresses how the discourses of one group or community work to challenge other community discourses. Every community discourse represents a separate counter-public sphere, and their struggle against each other works to redefine the limits of the "legitimate" public sphere discourse by shifting power from dominant discourses to those that are not yet fully represented to the overall public. It is these shifts of power and representation among counter publics that effectively radicalize the public sphere. In blogs, discourses are "two-way, relatively low cost, semi-decentralized and global" (p. 49) the potential for discursive radicalism and inter-discursive contestation and thus counter-publics, makes these sites an ideal locale for radicalized public sphere development.

The development of contestation relies on the exclusion of minority opinion inherent in the Habermasian public sphere. Dahlberg (2007) claims that, in any public sphere formation, discourse is labeled as legitimate or illegitimate. This creates a form of exclusion that allows non-dominant discourses, represented as counter-public spheres, to operate as a "radical outside" (p. 54) because they represent discourses that are not dominant, and are therefore not considered normal or legitimate. The existence and recognition of this "radical outside" then in turn "points to the dislocation of the social - the impossibility of closure of all discursive systems" and presents "the possibility for successful contestation and re-articulation of discourse" (p. 55) 
through the restructuring of illegitimate discourse as legitimate. In the context of discussion on blogs, this can occur through contestation of a majority opinion on a comment thread by a minority of users, or in a broader sense, by the development of counter-publics.

This study used Dahlberg's (2007) definition of counter publics as “alternative discursive arenas constituted by a number of participants engaging in debate and criticism that strengthens and develops oppositional discourses ... to those dominating the mainstream public sphere" (p. 56). Dahlberg claimed that counter publics can be developed through blogging and online commenting by employing discursive radicalism and inter-discursive contestation in these online spaces for discourse. These two types of counter public discourse serve as the alternative to the filtered, personalized version of online media that is centered on the dominance of community ideology and the exclusion of deviant comments from community-related media discourses.

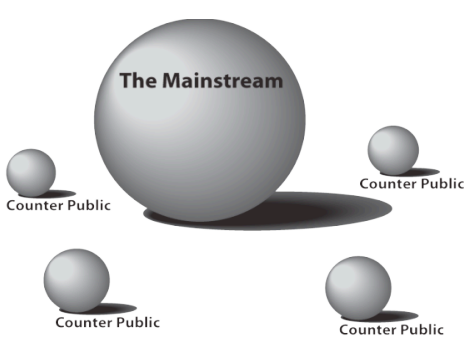

1.1: Counter public spheres develop outside of the mainstream public sphere

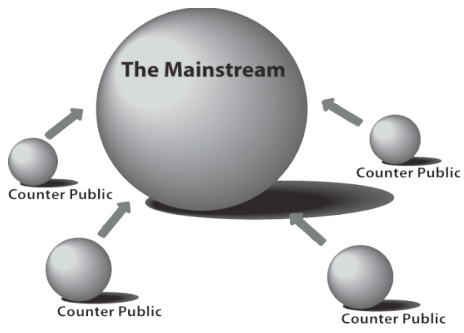

1.2: Through normalization and the dominance of discourses, the counter publics are incorporated into the mainstream public sphere.



1.3: Eventually, the mainstream public sphere gains dominance, and counter public spheres can no longer exist

Figure 1. The relationship between the mainstream and counter public spheres in the traditional model of public sphere discourse

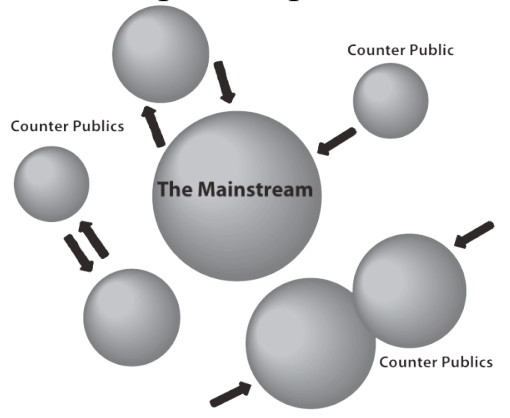

2.1: Discursive Radicalism

Counter publics existing outside the mainstream public sphere create discourses within themselves to challenge or promote dominant discourses in other counter publics or in the mainstream public sphere
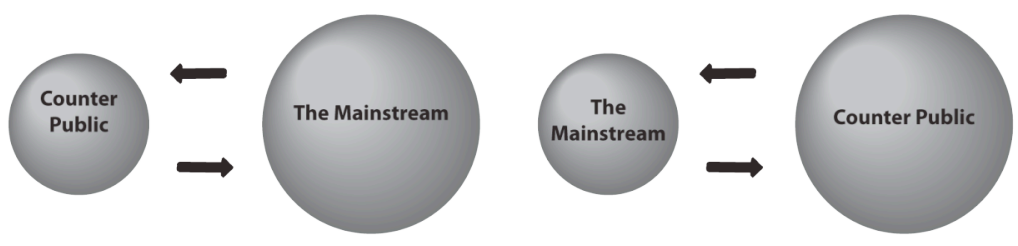

2.2 a: Inter-discursive Contestation

Counter publics work to challenge the dominance of the mainstream public sphere.
2.2 b: Inter-discursive Contestation

Through the shifting of discursive control, counter publics become the dominant public sphere, and what was the mainstream public sphere becomes a counter-public and takes on the function of challenging the dominant public sphere. 
Figure 2. The relationship between the mainstream and counter public spheres in the radicalized public sphere model of public sphere discourse.

When individuals create and seek out sites online devoted to a particular ideology or type of interest, this generates solidarity among those included in the group as well as those excluded from it. However, Dahlberg's (2007) concepts of discursive radicalism and inter-discursive contestation form a circular relationship between the included and excluded groups. The excluded group, according to Dahlberg, will form a counter-public through members shared experience and will develop discourses that challenge those of the dominant (included) groups. This creates discursive radicalism within the blogging community. With enough contestation of the dominant discourses by the counter-publics, the excluded groups will become dominant, and the formerly included groups will be pushed into the place of the excluded groups. From here, they will in turn contest the new dominant discourses through the system of inter-discursive contestation (p. 57).

Counter-publics are "actively constituted through their opposition to dominant culture" (Collingwood, 2007, p. 21) and are present in blogs as separate blog sites that exclusively deal with the opinions of, and news for, specific minority or special interest groups. With the development of counter-publics, radicalized democratic discourse can occur. Dahlberg defines radicalized democratic discourse as discourses in which "debate and criticism that strengthens and develops oppositional discourses $[\ldots]$ to those dominating the mainstream public sphere" (Dahlberg, 2007, p. 56). The development of such discourses in turn develops a radicalized form of the public sphere, which will, "actively and effectively contest the discursive boundaries of the mainstream public sphere" (p. 57).

\section{Normalizing Force}


The freedom the Internet allows its users also provides them with the means to selectively reinforce norms online by ignoring media that challenge their own views. Trenz (2009) described this effect by noting that, with the advent of the Internet, "never has it been easier for the citizens to opt for those news outlets that reflect their values and political affiliations and to filter out all news and opinions that do not immediately confirm to their world view" (p. 44). In addition to news filtering, blog users may selectively seek out only those sites that represent topics they are already interested in or opinions they already hold. This occurs, according to Trenz, because, "public communication is necessarily rooted in common culture and experience" (p. 37). Without a sense of shared purpose or culture within a discourse, the communication would become individual-based and would, by its nature, lose its publicness. For this reason, Dean (2001) claims that the disconnect between individual citizens and the texts they produce suggests that the public sphere is inapplicable to modern culture as it is developing online. The texts represent the collective, normalized perspective of a limited and typically exclusive community, rather than the complex array of different opinions held by individual citizens.

Additionally, Sebler (1996) suggests that, "what is often debated in online forums [...] is not whether participants speak the truth, but whether their speech is within the true of that specific discourse" (p. 276). In this way, online discourse like comment threads may be "policed" by participants to ensure that only the topics and opinions they consider to be appropriate in the context of the comment thread and the site as a whole are discussed. Sebler notes that commenters tend to resort to policing strategies, "when participants raise topics that potentially rupture relatively stable hegemonic relations" (p. 227). These policing strategies may involve complaining about a specific comment on the comment thread, complaining to the management of the site, or marking the criminal post as inappropriate in cases where the site 
provides such functions. The desired result of these policing actions is a discourse that represents only the ideas and perspectives perceived as appropriate and normal to the most frequent and most vocal commenters on any given thread. Commenters who wish to discuss topics that are contested on one site must either tolerate having the value of their post contested by the established users of that blog site, or they must relocate their attention to a site where their perspectives are in the norm.

Each of these theorists point to valid criticisms of the Internet as normalizing, selfinterested, and alienating; however, according to radicalized public sphere theory, each of these criticisms actually point to necessary aspects of the Internet's functions. Without some normalizing force, which Dahlberg (2007) suggests is often developed through the self-interest of dominating individuals, there would be no "struggle to discursively fix meaning within any social order" (p. 55). Without such struggle, there would be no discursive 'other' to bring about contestation. Without the ability to separate yourself from those you identify as 'others' an individual cannot develop an identity or find those he recognizes as the same as him. Furthermore, the anonymity Dean (2001) criticizes for separating bodies from words is essential, especially for marginalized groups. The sense of security it provides is necessary for the development of an online identity that labels and individual as an "other" to the mainstream.

The aim of this study is to understand whether blogs, and the comment threads that accompany them, are able to facilitate discursive radicalism and inter-discursive contestation. Dahlberg's concept relies on the use of normalizing force within dominant groups and counter publics to generate solidarity and enable members of these groups to supplant each other. Normalizing force, however, may also be used to maintain the dominance of one group, and could therefore work against Dahlberg's overall radicalized public sphere theory. 
In comment threads, if social controls begin to operate on comments and enforce norms, the ability of users to develop contesting opinions may be limited. Drawing from Foucault's (1975) work on the topic, social controls can be defined as the use of surveillance and discipline by individuals to regulate the actions of others in a society or community so that they are within the socially agreed upon definition of acceptable behavior. Foucault defines surveillance as a controlling gaze used to subdue and control those under its eye. He explains that surveillance "is a multiple, automatic, and anonymous power; for although surveillance rests on individuals, its functioning is that of a network of relations from top to bottom, but also to a certain extent from bottom to top and laterally" (p. 176). Thus surveillance can be used as a form of social control by seemingly placing power on the individual. Each individual operates as a lens for the overall power structure and is a means for control through the system of ranking and reporting. The desired result is every individual watching and noting other individuals' deviance from the norm, which will lead to more individuals behaving in accordance with the established rules of society.

In blogs, the concept of surveillance operates in the ability of individuals to view public blogs and the comments that follow them. Individuals willingly publish blogs, or comments on blogs, representative of their ideas or opinions to a public site, and the public surveys these blogs, seeking out bloggers with opinions or perspectives similar to theirs as well as informative articles on topics of interest to themselves. Occasionally, a reader may come across a blog post that they particularly like or dislike and may feel compelled to comment about this post on the post's comment board.

Commenting is the operationalized form of the next portion of Foucault's (1975) explanation of social control: discipline. Discipline, for Foucault, "is the specific technique of power that regards individuals both as objects and as instruments of its exercise" (p. 170). 
Foucault explains that discipline has the power to train individuals in such a way that they become "a multiplicity of individual elements" (p. 170) shaped by those in power to function as separate parts of a larger whole.

Foucault (1975) also suggests that "in discipline punishment is only one element of a double system: gratification-punishment” (p. 180). In Foucault's gratification-punishment system, discipline can be achieved through acts of punishment, which are typically designed to reduce a person's social standing, as well as through rewards or gratifications, which typically take the form of increased status or standing in one's society. Foucault claims that, through the gratification-punishment system of discipline, a "micro economy of perpetual penalty operates (as) a differentiation that is not one of acts, but of individuals themselves, of their nature, their potentialities, their level of value" (p. 181). So observed deviant behavior represents a reduction in individual, personal value, while observed preferred behavior represents increased personal value. In this way, a hierarchy for social status is developed that gives those at the bottom of the hierarchy a means to increase their status through exhibited normalized behavior, and social control is thus achieved.

In comments, hierarchizing discipline is achieved in multiple ways. Blogs with acceptable content according to the society associated with that blog are rewarded with positive comments that can take the form of support for the blogger with praise, with additional information to support the blogger's claim, or by marking the blogger as ranked higher than others using a scoring system adopted in some blog's publics. Blogs with deviant or unacceptable content receive comments against the blogger or the blogger's ideas. These can vary from a simple "I disagree" or "You're wrong" to drawn out arguments against the blogger's claim, to aggressive comments using vulgar language. Each form operates as a form of 
punishment for the blogger by pointing to some reason why his post does not conform to the established norms expected from such a post. Comments may also be directed at other comments, and this may operate in the same way they do when directed at posts. Punishing comments take on the same forms and are intended to make the deviant commenter's post less valuable, and by extension devalue the deviant commenter himself, while gratifying comments will support a commenter's comment, thus suggesting that the content of the comment and the commenter are more valuable than others.

\section{Research Questions}

To better understand radicalized public sphere development, this research project investigates how discourses in comment threads promote or limit discursive radicalism and interdiscursive contestation, two critical components of the radicalized public sphere. Discursive radicalism is the constant resistance to fixed meaning in discourse (Dahlberg, 2007). It can manifest itself in comments as any point intended to state, question, or improve understanding of a topic, thereby adding to, challenging, or altering its meaning to those involved in the discourse. Inter-discursive contestation is the constant shift in power between the mainstream public sphere and any number of counter-publics (Dahlberg, 2007). It can be apparent in comments as any remark intended to promote one norm over another, whether it be in support of mainstream norms or of those related to a counter public. An emphasis is placed on understanding the balance between comments that promote discourse, thereby enabling discursive radicalism, and those that promote norms. An imbalance in favor of normative comments could indicate a failure of radicalized public sphere discourse.

This study develops a system of identification that will allow the outlining and understanding of the diverse discursive strategies occurring within comment threads. By 
identifying these strategies and quantifying the frequency of their occurrence within the comment threads, the dominant discursive strategies can be identified and categorized as either promoting radicalized public sphere discourse or enforcing norms within the commenting community (McGee, 1980).

RQ1: Which discursive strategies are most prevalent within the comment thread?

In addition to identifying the dominant discursive strategies and their relationship to radicalized public sphere development, this study also works to identify the types of comments that occur in comment threads based on the rhetorical strategies employed to develop normalizing or discourse-promoting language in the comment threads. The relationship between comment types and discursive strategies will be recorded, and may improve understanding and enable future identification of discursive strategies that either promote or inhibit the development of a radicalized public sphere as they occur on other comment threads.

RQ2: What rhetorical strategies are employed in comment threads to encourage discourse or enforce norms?

\section{Method}

The nature of Internet communications, especially blogging and commenting, is subject to constant change and revision. Each comment posted to a comment thread has the potential to change the dynamics of the discourse occurring in the thread as a whole. Such change must be accounted for in this study to better represent the data under investigation and the generalizability of the results. Suggesting results are representative of online commenting as a whole would be incorrect, as comments and discourses are constantly changing with the advances in available technology. However, by employing rhetorical criticism in the analysis of 
the discourses in the proposed sample, this study seeks to provide insight into the "social reality" of the discourse (Wander \& Jenkins, 1972). Doing so will provide an outline of how commenting works in two unique online communities, thus providing a guideline for future, more generalizable research and theory development on the topic as it evolves. Furthermore, the radicalized public sphere theory calls for constant change and contestation, so recognition of the changing nature of online commenting suggests a potential point of success for Dahlberg's theory and is a critical part of this study.

\section{Ideological Criticism}

This study relied on the rhetorical method of ideological criticism to form the basis for the examination of the observed blogs. It used Foss' (2004) definition of ideology as "a pattern of beliefs that determine a group's interpretation of some aspect(s) of the world" (p. 239) and expand it to include individual ideologies as well as group ideologies. It is necessary to recognize individual ideology in this study to account for the format of comment threads, which allow for individual contribution and discussion as well as grouping of individuals by ideology. This is reflective of the postmodernist approach to ideological criticism, in that it accounts for "fragmentation of individuals, alienation, and a destabilization of unifying discourses and principles" (p. 241). In addition to the postmodernist approach, a structuralist approach to ideological criticism, with an emphasis on the use of words as signs that are indicative of deeper meaning, will be employed to study the meaning displayed in the comment posts.

The emphasis on the ideology of the text was incorporated into this study because understanding the ideology of a discourse allows for better comprehension of how that discourse is being controlled (McGee, 2008; Rushing \& Frentz, 1991). As McGee (1980) explained, "ideology in practice is a political language, preserved in rhetorical documents, with the capacity 
to dictate decision and control public belief and behavior. This type of power over public thought, according to the definitions used in this study, could be considered a form of normalizing social control (Foucault, 1974). If one accepts that social controls can manifest themselves in rhetorical documents (McGee, 1980) then it stands to reason that by identifying the ideologies within individual comments, this study is also identifying the social controls employed in comments to normalize discourse. By doing so, a better understanding of how these social controls are used, and whether they dominate the online discourses in comment threads can be achieved.

Following Foss's (2004) instructions for doing ideological criticism this study was completed in four stages. First, the artifacts for the study must be selected. This study will begin with an initial set of three hundred interactions, which was defined as any comment made in response to a previously posted comment, taken from two blog sites that attract different audiences and interest groups. Each blog site must provide open, un-moderated or minimally moderated commenting on their blog posts to allow for the best user-generated discourse. They must also provide enough diverse material related to the topic they cover be able to generate attention from users with varying interests that may have opinions that contest with other users of that site. Blogs developed from traditional media sites, such as the New York Times, CNN, or Fox news will be excluded due to the broad scope of news coverage and mass audience appeal. Using the above criteria, the blogs chosen for observation in this study will include treehugger.com and techcrunch.com. Both of these blogs represent a different community and are capable of drawing users with different, deviating interests to their site.

Comment threads used in this study must include at least one interaction between commenters to be considered for observation and analysis. Blog posts with fewer comments may 
not present discourses developed enough to exhibit any contestation, rule-making, or social controls, because comments may not receive responses from other users, and therefore operate as stand-alone comments rather than discourse among a community of users. This limitation will help to exclude comment threads where a small number of users post basic responses to the blog post but do not develop any discussions out of those posts. The archives for each blog will be used to obtain acceptable posts. From each blog, the first 300 interactive comments from a randomly selected month will be used for this study. Current or recent posts, specifically those made in the last three months, cannot be used, as additional comments may be made to posts as time passes, which will alter the post's eligibility for this study. Due to the large number of posts being published on a blog every day, posts over one month old usually receive very little attention from users and are therefore more easily considered for eligibility because these threads are more likely to contain complete conversations. The initial set of posts and threads chosen for observation will include the first eligible post from each blog posted on the first day of the month chosen for observation.

Using the proposed sample, the second stage of the study, the analysis, can begin. Foss (2004) suggests that the analysis of an artifact should be completed in two stages. First, the researcher should identify the ideology present in the artifact. This is done through a close analysis of the artifact to understand conceptualizations of membership, activities, goals, values or norms, group relations, and resources that shape the overall ideology present in the artifact. Part of identifying the ideologies of a text involves incorporating the researcher's personal experience and relationship to the data into an analysis of the meaning behind the words being studied (Wander \& Jenkins, 1972). To assist in the analysis, the definition of ideology as a set of individual or group beliefs that operate to shape one's thoughts will be employed as a general 
guide for the study (Foss, 2004). Definitions from the literature, especially those related to normalizing force and radicalized public sphere discourse, will also be used to assist in the identification of comments as presenting norm- or discourse-promoting ideologies (Dahlberg, 2007; Foucault, 1974). The details of these interpretations, however, are left to the researcher's personal understanding and analysis of the data, and find their validity in the support the critic provides for his analysis (Wander \& Jenkins, 1972).

Once the ideology is identified, the researcher should progress to the second stage of analysis, in which the rhetorical strategies employed within the artifact to support the ideology are identified. The rhetorical strategies should be subject to the same analytical standards of identification as the ideologies before them. Identification of these strategies functions as a means to explain how an ideology is developed in a discourse, as well as a source of support for the critic's claims about the identified ideologies. Because of the large number of comments, and therefore the potential for a diverse set of ideologies within the proposed sample, this study will incorporate the constant comparative method, a grounded theory approach to data sorting, to code the data in the sample.

\section{Constant Comparative Method}

In the constant comparative method, incidents (in this case, comments) are studied in four stages. The first stage involves, "comparing incidents applicable to each category" (Glaser, 1965, p. 439). Each incident is studied separately, then compared to previously coded incidents to find which category it best fits in. As incidents are compared and coded, the researcher begins to establish the theoretical properties of each category through the standards by which he or she uses to place an incident in a category. The researcher should use memos to make note of the 
theoretical properties that develop, and should take the time to ensure that the properties represent the most logical conclusions that may be drawn from the data.

In the second stage, categories are formed and comparisons begin to take place between incidents and categories, rather than incidents and other previously coded incidents (Glaser, 1965). Through both stages of constant comparison, "the accumulated knowledge on a property of the category $[\ldots]$ readily starts to become integrated, that is, related in many diverse ways resulting in a unified whole" (p. 440). Once the categories begin to become theory-based and more abstract, the third stage can begin, where categories are reduced to a smaller set of higherlevel concepts, which are based on similarities between the original categories (Glaser, 1965). The main categories, or "core category" are then developed into a generalizable theory through further reduction and notes on uniformities throughout the categories. The generalizability of the developed theory grants it the parsimony and scope necessary to grant is validity in the study.

In the final stage, the theory is written. The researcher pulls from his or her memos to, "provide the content for the categories, which are the major themes of the theory" (Glaser, 1965, p. 443). The memos and coded data are the source of validity for the research, and allow the researcher to "pinpoint the data that backs their hypothesis or that closes gaps in their theory" (p. 443). In this way, the data serves as a guide to how the researcher came to his or her conclusions and developed the theory. In this study, because the goal of this research is to understand and identify the types of comments being used on blog sites, the theory-development stage will not be employed fully. Codes will be grouped into categories, and those categories organized and regrouped into broader categories until one dominant category is identified. A theory, however, will not be developed out of these categories. Rather, the ideologies present in the identified 
major categories will be incorporated into the analysis to suggest how they operate within the discourse to promote or inhibit the development of a radicalized public sphere.

The use of the constant comparative method is especially important because a large number of individual comments will need to be collected and coded, and coding these comments as they are collected, rather than all at once, will allow for better analysis of the data. Coding the comments as they are collected will allow for the integration of new concepts discovered in the texts into the overall theory being developed. This point is vital for the process of identification, both of concepts and of larger categories from the concepts in this study, as it allows for change in the standards of analysis rather than establishing set categories for coding before beginning the analysis.

Finally, the emphasis in grounded theory on the context of the data is also helpful in conducting an analysis of comment threads. Corbin and Strauss (1990) state that, in grounded theory, "the aim is ultimately to build a theoretical explanation by specifying phenomena in terms of conditions that give rise to them, how they are expressed through action/interaction, the consequences that result from them, and variations of these qualifiers" (p. 9). In looking at comment threads, it is important to approach each comment as both the action of an individual and an interaction among multiple individuals making up a community. Comments need to be observed both for the content they present and the context in which they appear within the thread. This is because there are a multitude of factors, including the subject of the blog post, the content of the comments preceding the comment being observed, the response from other commenters to the comment, and the overall theme of the comment thread at the point the comment is being posted, that can have an effect on the meaning of the observed comment. So, by observing both the comments themselves and the context they appear in, a much richer 
understanding of commenting can be gained, and insight into what sort of situations, discourses or comments generate particular types of comments, social norms, or rules in the discourse.

Once coding using the constant comparative method is complete, the data can be used to complete Foss' (2004) final stages of ideological criticism; formulating research questions and presenting the results of the study. In accordance with Foss' method, the research questions presented in the previous section of this paper were developed after the data analysis was completed and incorporated questions developed during analysis as well as concepts presented in earlier sections of this project. The research questions are presented before the method section to provide context for the reader, and to assist in illustrating the reasoning behind this choice in method as well as claims made in the discussion section.

\section{Study Design}

The initial set of posts and comments will be read and coded as they are collected, with notes taken on which category the comment applies to, and how it relates to the research that guides this study. These notes will be used to develop the initial concepts and categories in the initial stage of the constant comparative analysis. Notes will also be taken on the subject matter of the initial blog post that started the comment thread, and which site the post was made to, to account for variance among different communities as well as the context of each thread in relation to the site it occurred on.

Each blog post and comment thread selected for study after the initial posts will be observed for additional examples of the concepts and types of comments established in the initial review of the first posts. Coding will be done in a manner that will note the frequency and context of the appearance of the already coded types of comments, social controls, and rules, and to also take note of any additional types that were not presented in the first posts. Each comment 
will be identified in the notes by its relationship to a category. When all of the eligible posts from the selected time frame are coded and categorized, a second coding will be conducted based on notes from the first coding and review of the posts to determine any categories that apply to multiple concepts and fill in any gaps in the data where concepts do not have enough support to suggest an important place in the data identification.

Finally, the data will be quantified to show how frequently each type of comment, type of social controlling mechanism, or type of rule appears in comments on each blog. Data will also be quantified to show how frequently contestation appears on blogs and is successfully accepted in the discourse or is subdued by social controls present in the discourse. This data, in addition to the rich data available from analysis of the comments and the identifications of the types of comments, social controls, and rules, will be analyzed to find any links between the use of social controls and the development of contestation on blog posts. Additional analysis will be done on the posts to each blog, to determine whether there is any relationship between the frequency of social controlling comments and the development of contestation.

\section{Analysis}

The following outlines the results of this study as they were developed and identified during the process of coding and analysis. In this study, two types of comments were coded. "Initiators" were identified as comments that received replies from other comments. “Comments" were any comment posted in reply to another, previously posted comment. Initiator comments, because they are not themselves interactive, were counted separately from the comments. However, because they are a part of the discursive comment thread (the entire series of interactions posted on a blog), the data is included in the analysis. 
For the purposes of this analysis, the term blog refers to the individual blog post that a commenter responds to, rather than the blog site as a whole. The term "author" is used to identify only the author of the blog that has generated the comment thread under observation. "Previous commenter" was used to identify any other commenter to whom a comment was addressed. "Previous commenter" could refer to the commenter immediately before a comment, or one who posted a comment earlier on in the thread, depending on the context of the comment under observation. Similarly, "previous comment" was used to refer to any comment occurring in the thread before the comment under analysis. The individual who created the comment under observation was termed the "user." "Users," thus, refers to all parties, both commenters and authors, who post to the blog. ${ }^{1}$

\section{Treehugger.com}

Coding for this project began with comments from treehugger.com. Initially, notes were taken on the strategies used in the comments as a whole to identify the overall purpose of the comment. This strategy, however, did not effectively account for the variety of discursive strategies presented in a comment. To account for this, each sentence within the comment was given its own code to explain its function within the discourse. Each code was recorded, and subsequent sentences that met the criteria for a code that had already been created were tallied below it. Sentences that did not apply to any of the identified codes were given their own code, which was then incorporated into the notes.

Codes eventually began to develop that were similar in nature to others but bore small differences in the way they functioned within the discourse. These codes were grouped together under a broader category title (Table 1). Multiple codes that were similar in their function were

\footnotetext{
${ }^{1}$ For a list of definitions and examples for the categories identified in this study, see Appendix.
} 
re-named and combined. Those that remained functionally different from the others retained their original designation, but were included under the broader category designation.

Table 1

Initial development of categories

\section{Questioning}

Questioning the purpose of the blog

Questioning a concept presented in the blog

Questioning author's use of a specific word

Questioning concept presented in previous comment

Asking previous commenter a question

Asking a generalized question related to topic

Asking for more information on a topic

Asking users for alternative ideas

Questioning the beliefs of the blogger to discredit

Questioning broader topic related to blog

For example, the comment from the user waltinseattle, in which he states, “...I'd like some explanation and number crunching to defend the claim that it sequesters 110 kilos of $\mathrm{CO} 2$ per cubic meter" was codes as "questioning a concept presented in the blog." Waltinseattle's comment is phrased in a way that could be interpreted as asking for more information, however, his request for an explanation of the statistic cited in the blog, rather than working as a request for additional statistics, operates to question how the information that was presented was developed, and whether it is valid. The comment from JRT256 asks the question, "Do you have a citation link for the statement about the US potential reserves vs Saudi Arabia reserves" was coded as "asking for more information on a topic." The comment had the potential to operate as a form of questioning a previous commenter's claim, in that it calls into question the validity information presented by a previous commenter, however, because JRT256 refrained from questioning the previous commenter's opinion, and used neutral language to simply ask for a citation, this comment was coded in the more neutral category. Each of the above comment was 
identified as a distinct code, but because the primary function of both was to question some aspect of the discourse, both codes were incorporated under the questioning category.

As the list of categories developed, each was grouped under a broader category title that described the general function of its subcategories and the codes within them (Table 2). For example, the codes "questioning the purpose of the blog" "questioning a concept presented in the blog" "questioning the author's use of a specific word" and "questioning concept presented in a previous comment" were some of the codes identified in the initial coding stages. From these the categories "questioning blog" "questioning blogger" and "questioning previous commenter" were formed. The codes "questioning the purpose of the blog" and "questioning a concept presented in the blog" fell under the category "questioning blog," the code "questioning the author's sue of a specific word" was grouped under the category "questioning blogger," and the code "questioning concept presented in a previous comment" was placed in the "questioning previous commenter" category. Each of these categories then became sub-categories under the broader category title of "questioning." 
Table 2

Development of sub-categories

\section{Questioning}

Asking for more information

Asking a generalized question related to topic

Asking for more information on topic

Asking users for alternative ideas

Questioning Blogger

Questioning the beliefs of the blogger to discredit

Questioning author's use of a specific word

Questioning Blog

Questioning the purpose of the blog

Questioning a concept presented in the blog

Questioning a broader topic related to the blog

Questioning a Previous Commenter

Questioning concept presented in previous comment

Asking previous commenter a question

The examples from waltinseattle and JRT256 can illustrate this development of sub-categories.

While each served the purpose of questioning a concept within the discourse, the comment from

waltinseattle, which was coded as "questioning a concept presented in the blog" questioned a

vastly different part of the discourse than JRT265's comment, which was coded as "asking for

more information on a topic." To achieve a more detailed account of the purposes of these

comments within the commenting category, waltinseattle's comment was included in the

“questioning blog” sub-category, while JRT256's comment was grouped within the "asking for

more information" sub-category.

The same process was applied to all of the individual codes as they were identified.

Codes that did not fit into a category or subcategory were recorded, and integrated into new

categories as the coding process progressed. After coding the stated 300 comments in the sample

from treehugger.com, a total of 20 categories were identified (Table 3). 
Table 3

Categories from treehugger.com

$\begin{array}{ll}\text { Questioning } & \text { Agreeing } \\ \text { Criticizing } & \text { Disagreeing } \\ \text { Stating Opinion } & \text { Sarcasm and Joking } \\ \text { Providing Information } & \text { Reasoning } \\ \text { Personal Experience } & \text { Salutations } \\ \text { Correcting } & \text { Rule-making } \\ \text { Answering } & \text { Sloganing } \\ \text { Direct Quoting and Citing } & \text { Thanking and Complimenting } \\ \text { Exclamations } & \text { Plugging } \\ \text { Hierarchizing } & \text { Apologizing }\end{array}$

Each of these categories was broken down into subcategories based on the intended purpose of the sentence being coded. The category questioning, for example had sub-categories for “countering blog" "countering previous commenter" "supporting blog" "supporting previous commenter" and "supporting claim." Most of the categories included these sub-categories. If there were no codes to represent one of the five aforementioned sub-categories within a category, the sub-category was not included on the code sheet for that category. There were no codes, for example, for comments in the "countering blog," "countering previous commenter" and "supporting claim" sub-categories within the category for agreeing.

Additional sub-categories for codes that did not meet the definitions of any of the above sub-categories were included in the appropriate category. The questioning category, for example, also included a sub-category for "general questioning" (Table 4). When necessary, separate codes within the sub-categories were listed to separate data that served the same purpose under the sub-category, but achieved its function in a different manner. The sub-category "countering blog" included two separate codes, one for "questioning claim/concept presented in blog" and the other for "rhetorical question to counter blog's claim." Comparing the previous example 
from waltinseattle with a comment from Thomas Zell illustrates the distinction and similarities between these two codes. Thomas Zell writes, in response to a blog post about the morality of eating octopus based on the discovery that they are self aware, "So, are all the animal rights activists and cultural imperialists going to ban calamari now? After [all], only backwards barbaric societies like that Japanese eat squids regularly." The overall tone of sarcasm in both sentences of Thomas Zell's comment indicate that he disagrees with the idea presented in the blog that eating a cephalopod may be immoral. However, his question is phrased such that it does not invite an answer, and is therefore considered a rhetorical question. It is intended to criticize the groups who would agree with the concept in the blog, and through its phrasing, also functions to criticize the concept in the blog. It as therefore coded as a "rhetorical question to counter blog's claim." Waltinseattle's comment, as a contrast to Thomas Zell's, did question a piece of information presented in the blog, but did so in a manner that would invite a response from the blog author or another commenter, and so was grouped in the "questioing claim/concept presented in blog" sub-category. Waltinseattle's comment sought information while pointing out a potential flaw in the blog's claim, whereas Thomas Zell's comment only operated to discredit and argue against a concept in the blog, and did not invite further discussion. 
Table 4

Example of Category Break-down from Treehugger.com

\section{Questioning}

Countering Blog

Questioning claim/concept presented in blog

Rhetorical Question to counter blog's claim

Countering Previous Commenter

Questioning claim/concept presented in p. concept

Asking p. commenter a question

Rhetorical question to counter $\mathrm{p}$. commenter

\section{Initiators Comments}

21

5

$6 \quad 0$

$0 \quad 35$

$1 \quad 4$

$0 \quad 43$

Supporting Blog

Rhetorical question to support blog $\quad 0 \quad 2$

Asking for more information

Supporting Claim

Rhetorical question to support claim

Challenging others to prove why user's concept is wrong

10

7

0

1

General Questioning

Asking for more information

Explaining reason for asking question

Asking generalized question related to topic

$5 \quad 0$

12

32

Supporting Previous Commenter

Rhetorical question to support p. commenter's claim

0

2

Once coding was complete, the twenty categories identified in the study were re-worked into three new categories: gratifying, punishing, and discourse-promoting. Codes falling under the gratifying category followed Foucault's (1974) definition of gratification as a form of social control, in which comments operate to increase the social standing or authority of a user on the blog, either the commenter themselves or a previous commenter, over others. Similarly, codes falling under the punishing category met Foucault's definition of punishment, in that the 
comments worked to reduce social standing or authority of a user on the blog. Codes identified as discourse-promoting met the definition of Dahlberg's (2007) concept of discursive radicalism, in which dominance over a discourse is inhibited via the challenging of normalizing comments.

Within the gratifying category, codes typically involved the commenter showing support for either the blog, a previous commenter, or themselves (Table 5). The hierarchizing nature of a gratifying comment was emphasized by incorporating language which suggested that the individual the comment supported was ideologically, morally, or logically right. In coding for this category, the initial category "questioning" was split into two sub categories, "questioning" and "rhetorical questions." Rhetorical questions were presented on the blog as questions used to discredit another user, as well as questions that subsequent users were not intended to answer, and as such were incorporated into the gratifying and punishing categories. 
Table 5

Totals for Gratifying Category from Treehugger.com

\section{Gratifying}

Rhetorical Question to support p. com

Rhetorical Question to support blog

Rhetorical Question to support claim

Criticizing to Support Previous Commenter

Criticizing to Support Claim

Agreeing with blog

Agreeing with previous commenter

Sarcasm or joking to support claim

Sarcasm or joking to support previous commenter

Sloganing

Direct Quoting to support previous commenter

Direct Quoting to support claim

Rule-making to support claim

Exclamation to support claim

Exclamation to support previous commenter

Hierarchizing to support blog

Hierarchizing to support claim

Hierarchizing to support previous commenter

Scorekeeping

Thanking and Complimenting

\begin{tabular}{|c|c|}
\hline Initiators & Comments \\
\hline 0 & \\
\hline 0 & \\
\hline 10 & \\
\hline 0 & \\
\hline 0 & \\
\hline 7 & \\
\hline 3 & \\
\hline 2 & \\
\hline 0 & \\
\hline 3 & \\
\hline 0 & \\
\hline 0 & \\
\hline 4 & \\
\hline 1 & \\
\hline 0 & \\
\hline 12 & \\
\hline 11 & \\
\hline 0 & \\
\hline 0 & \\
\hline 1 & \\
\hline
\end{tabular}

Comments the gratifying category varied greatly in the rhetorical strategies employed to achieve their purpose. Something as simple as Liam Casey's comment, "I agree with this completely," which was included in the agreeing category, worked as a means to gratify another user. In Liam Casey's case, his comment operated as a way to state his agreement with a previous commenter. Making such a statement was perceived as promoting the concept of one user over others, and was thus grouped within the gratifying category. Other comments employed similar hierarchizing strategies, such as Rdx's comment, “Oh, well excuse my grammar, I scored 720/800 on my GRE btw :P.” This comment, made in response to a previous user who pointed out a grammatical error in Rdx's comment as a way to discredit his claim, was 
coded as "hierarchizing to support claim". Its function is to illustrate Rdx's intellectual superiority over other commenters by citing scores from a standardized test, thereby establishing a hierarchy of users based on intelligence, with Rdx placed higher than other blog users.

Brspaworks' statement that, "GOD said we can eat anything that swims in the ocean, and anything that flies in the air. case closed" works to illustrate the rule-making sub-category of gratification. In this case, Brspaworks evokes the word of God as the basis for his or her rule in the context of the blog she is commenting on. This works to suggest that the rule he or she uses, and therefore his or her own claim, is the definitive judgment on the discussion. Thus, Brspaworks' comment functions as a form of self-gratification, suggesting that he or she is more right than other users in the discourse. In each case, the user incorporates a statement of rightness, either directed toward themselves or another blog user, to establish a hierarchy in favor of the opinion they support. This, in essence, is gratification.

Codes within the punishing category incorporated comments from many of the same initial categories as those that were integrated into the gratifying category, but included those codes that were intended to counter the blog or other commenters, rather than support them (Table 6). Codes that were included in this category were created with the intent to discredit or prove wrong either the blog or a previous commenter, thereby de-valuing the claims from those users. The previous example from Thomas Zell is an excellent example of a punishing comment. Thomas Zell's rhetorical question, "So, are all the animal rights activists and cultural imperialists going to ban calamari now" operates to counter the blog, and also suggests a hierarchy of concepts in which the information presented in the blog is held at a lower standing.

Punishing comments, unlike gratifying comments, often integrated insulting as a way to discredit and lower the social standing of another user. This was typically done by insulting 
another user's intelligence, as in the comment from the aptly named user Rocky fisher is an idiot, in which the user exclaims to the previous commenter, "You are nuts, just lock our kids up in padded rooms for fuck sake. Just ridiculously stupid.” The insulting trend is apparent in a less aggressive tone from Uncle_Ben's comment, “...your ignorance is alarming and it is clear you are missing the entire point of choosing to eat something that is organic." In both cases, the user is employing insulting language to suggest a hierarchy based on intelligence, in which the commenter they are insulting is to be held in low ranking.

In Rocky fisher is an idiot's comment, the first sentence was coded as “criticizing to counter the previous commenter" because it functioned to counter the previous commenter's claim as well as insult. The second sentence was coded as "hierarchizing to counter pervious commenter," because the intent was only to insult and reduce the standing of the commenter it was attacking. Uncle_Ben's comment was coded as "criticizing to counter previous commenter" as well, due to its emphasis on countering the previous commenter's beliefs on consuming organic food as well as its intent to insult. In each case, punishment was the intended purpose of the comment. 
Table 6

Totals for Punishing Category from Treehugger.com

Punishing

Rhetorical Question to counter p. com

Rhetorical Question to counter blog

Criticizing to counter blog

Criticizing to counter previous commenter

Disagreeing with blog

Disagreeing with previous commenter

Sarcasm or joking to counter blog

Sarcasm or joking to counter previous commenter

Direct Quoting to counter blog

Direct quoting to counter previous commenter

Rule Making to counter previous commenter

Argumentative exclamations

Exclamations to counter blog

Exclamations to counter previous commenter

Hierarchizing to counter blog

Hierarchizing to counter previous commenter

Suggesting general hierarchies

\begin{tabular}{rr} 
Initiators & \multicolumn{2}{c}{ Comments } \\
0 & 43 \\
6 & 0 \\
35 & 31 \\
0 & 39 \\
1 & 1 \\
0 & 6 \\
6 & 5 \\
0 & 37 \\
5 & 3 \\
0 & 25 \\
0 & 1 \\
0 & 3 \\
3 & 4 \\
0 & 5 \\
3 & 4 \\
3 & 51 \\
21 & 16
\end{tabular}

The discourse-promoting category incorporated the categories that encouraged discursive radicalism through questioning and information-sharing between users, and that did not specifically operate to promote or decrease the standing of any blog users within the thread (Table 7). Some of the initial categories were grouped together under a broader category due to their similar functions within the discourse-promoting category. The categories "providing information" "citing personal experience" "correcting" "answering” and "citing sources" were grouped under the broader title of "providing information" and identified as sub-categories under that designation because each of the initial categories worked to provide a form of information, albeit in a different manner from the others. Compare, for example, the following two comments: 
Steve I use rechargeable batteries in mine at home and have only recharged them once in the last year, so it's no an issue for me.

waltinseattle compared to cotton...tries faster, like silk or

nylon...insulates better because (it) is hollow like the best synthetics we make...and does not require the 300 plus gallons for a t-shirt that cottons uses..."

Steve's comment was initially coded as "citing personal experience," while waltinseattle's remark was identified as “providing information. In both cases, additional information is presented in the discourse. Steve's comes from his own experiences, waltinseattle's from his personal knowledge of a topic. The ultimate function of each comment is to inform other users, therefore each is grouped within the larger category of "providing information" and sub-categorized based on the type of information, personal, technical, or otherwise, that is provided.

The category for "direct quoting" was also split to allow for the direct quoting comments, which worked as normative comments, to be grouped in either the gratifying or punishing categories while allowing the "citing sources" code, which functioned only to provide additional information to blog users, to be incorporated both into the "providing information" sub-category and the discourse-promoting category. Codes that appeared neutral in nature, specifically the "salutations" sub-category, were included in the discourse-promoting category because they operated as a rhetorical function of the dialogue that seemed to encourage civil conversation amongst the blog users by mimicking the style of a person-to-person dialogue or personal letter, and because they did encourage any normative discourse, either gratifying or punishing, in their content. 
Table 7

Totals for Discourse-Promoting Category from

Treehugger.com

Discourse-Promoting Comments

Questioning

Questioning a claim or concept presented in the thread

General Questioning

Stating Opinion

Stating an opinion

Suggesting a middle-ground solution

Providing Information

Providing additional information

Citing personal experience

Correcting

Answering

Citing sources

Plugging

Plugging a product

Plugging a blog

Apologizing

Reasoning

Salutations

Signing a post

Greeting a commenter

Exchanging pleasantries

\section{Initiators Comments}

$\begin{array}{rr}22 & 44 \\ 10 & 4 \\ 120 & 163 \\ 3 & 22 \\ & \\ 99 & 308 \\ 127 & 129 \\ 11 & 66 \\ 5 & 14 \\ 6 & 7 \\ & \\ 0 & 6 \\ 0 & 1 \\ 0 & 1 \\ 9 & 12 \\ & \\ 1 & 5 \\ 0 & 3 \\ 0 & 2\end{array}$

After separating codes into the categories for gratifying, punishing, and discoursepromoting comments and totaling the number of codes in each, the gratifying and punishing categories were merged to become sub-categories within the broader category of normalizing comments (Table 8). This was done to account for Foucault's (1974) claim that both gratification and punishment work as functions normalizing forces within a society. Although some of the normalizing comments promoted counter-public rather than mainstream norms, these were categorized under normalizing. Normative discourses, both those that support and contest the mainstream public sphere norms, are a critical function of inter-discursive contestation. The 
importance of the data on normalizing comments lies in its relationship to the discourse-

promoting category more than in the norms it promotes. Totals for the number of codes in both the normalizing and discourse-promoting categories were taken, and converted into percentages for the total number of codes from the treehugger.com data. The entire process of coding was done for the three hundred interactive comments, as well as all of the comments that functioned as initiators of interactive comments, but did not operate as interactions themselves. Initiator comments were coded separately from the interactive comments, but were put through the same process of categorizing and re-categorizing within the constant comparative method.

Table 8

Normalizing and Discourse-Promoting Category Totals

from Treehugger.com

Normalizing

Gratifying

Punishing

Total

Percentage

\section{Discourse-Promoting}

Questioning

Stating Opinion

Providing Information

Plugging

Apologizing

Reasoning

Salutations

Total

Percentage

$\begin{array}{rr}\text { Initiators } & \text { Comments } \\ 54 & 161 \\ 83 & 275 \\ & \\ 137 & 436 \\ 24.91 \% & 35.65 \%\end{array}$

32

123

248

0

0

9

1

413

$75.09 \%$
48

185

524

7

1

12

10

787

$64.35 \%$

Totals from the treehugger.com data show that discourse-promoting interactive comments were more frequently used in the comment threads than normalizing interactive comments, by a margin of 28.7 percentage points. The same is true, to a greater extent, for 
initiator comments, which showed a margin of 50.18 percentage points between the discoursepromoting and normalizing categories.

\section{Techcrunch.com}

Coding for the techcrunch.com data took place immediately after the conclusion of the treehugger.com data coding, and before the reorganization of the twenty initial categories identified in the treehugger.com data into the final three identified categories. To streamline the coding process for the techcrunch.com data, the codes and categories identified from the treehugger.com data were used as an initial framework for the code sheets for the treehugger.com coding. Comments that met the same criteria for a code as the treehugger.com data were counted within the code and category to which they applied. Comments that did not fit within the definitions of any of the identified codes or categories were coded according to their nature within the discourse, and the code sheets were expanded to incorporate any new codes or categories that were identified. Only one new category, networking, arose from coding the techcrunch.com data (Table 9). Comments within the networking category functioned to utilize the comment thread as a connection-making tool with which users could meet and benefit from interactions with other users. The codes within this category included "asking previous commenter for an interview" "providing personal info to previous commenter" and "asking for free products." One example, from the techcrunch.com user Mark, illustrates comments category well:

Mark Hey Alexis. Is there a Reddit meet up event planned? We did submit Gokode to YC. If your offer stands and you can give me a few minutes at the Rally, I would love the chance to elevator pitch it to you.

The final sentence of Marks' comment was coded as “asking previous commenter for an interview" and placed within the networking category. The conversation between Mark 
and the previous commenter, Alexis, had been developing for several comments before the request for a chance to pitch Mark's product was issued. Alexis was identified on the blog as a person of authority in the technology industry, and used her own name to reply to comments from several other users. Mark took the opportunity to develop a conversation, form a connection with Alexis, and use that connection to request an opportunity to pitch his product to her. This type of discourse, though potentially beneficial to the user who takes advantage of such opportunities, is essentially discoursepromoting, in that it encourages conversations and the exchange of ideas between users both in the online discursive space of the comment thread as well as in a real-world setting.

Table 9

Codes within the Networking Category

Networking

Asking P. commenter for an interview Providing personal info to $p$. commenter Asking for free products
Initiators Comments $0 \quad 1$ $0 \quad 1$

$1 \quad 0$

If a code or category on the code sheets from the treehugger.com data was not identified within the techcrunch.com data set, that code or category was removed from the code sheet for the techcrunch.com data at the end of the coding process (Table 10). For example, the codes for “challenging others to prove why user's concept is wrong" and "explaining reason for asking question" were removed from the code sheet for the category "questioning" at the completion of the techcrunch.com data coding because there was no data identified within those codes. The categories removed from the techcrunch.com code sheets were not removed from the treehugger.com code sheets, because the categories from that set of codes contained data. 
Table 10

Example of Category Break-down from Techcrunch.com

\section{Questioning}

Countering Blog

Questioning claim/concept presented in blog

Rhetorical Question to counter blog's claim

Countering Previous Commenter

Questioning claim/concept presented in p. concept

Asking p. commenter a question

Rhetorical question to counter $\mathrm{p}$. commenter

Supporting Blog

Rhetorical question to support blog

Supporting Claim

Rhetorical question to support claim

General Questioning

Asking for more information

Asking generalized question related to topic

Supporting Previous Commenter

Rhetorical question to support p. commenter's claim

\section{Initiators Comments}

10

3

17

5

12

5

022

1

0

7

2

22

5

0

1

After completing coding for the techcrunch.com data and removing or adding categories and codes where necessary, the data was re-categorized along with the treehugger.com data (Tables 11 and 12). Because the codes and categories in the initial coding of the techcrunch.com represented the same functions as those identified in the treehugger.com coding, each code and category from techcrunch.com was separated, reorganized, and placed in the same broader category as its counterpart from the treehugger.com data. Codes that were not identified and removed from the code sheets after the initial coding of the techcrunch.com data were not included in the re-categorization of the data. 
Table 11

Totals for Gratifying Category from Techcrunch.com

\section{Gratifying}

Rhetorical Question to support p. com

Rhetorical Question to support blog

Rhetorical Question to support claim

Criticizing to Support Previous Commenter

Criticizing to Support Claim

Agreeing with blog

Agreeing with previous commenter

Sarcasm or joking to support claim

Sarcasm or joking to support previous commenter

Sloganing

Direct Quoting to support previous commenter

Direct Quoting to support claim

Rule-making to support claim

Exclamation to support claim

Exclamation to support previous commenter

Hierarchizing to support blog

Hierarchizing to support claim

Hierarchizing to support previous commenter

Scorekeeping

Thanking and Complimenting

\begin{tabular}{rr} 
Initiators & \multicolumn{2}{c}{ Comments } \\
0 & 1 \\
1 & 0 \\
7 & 2 \\
0 & 0 \\
0 & 0 \\
0 & 0 \\
0 & 30 \\
4 & 1 \\
0 & 22 \\
2 & 0 \\
0 & 0 \\
0 & 0 \\
0 & 0 \\
0 & 1 \\
0 & 3 \\
2 & 0 \\
12 & 32 \\
0 & 0 \\
0 & 2 \\
1 & 5
\end{tabular}


Table 12

Totals for Punishing Category from Techcrunch.com

Punishing

Rhetorical Question to counter p. com

Rhetorical Question to counter blog

Criticizing to counter blog

Criticizing to counter previous commenter

Disagreeing with blog

Disagreeing with previous commenter

Sarcasm or joking to counter blog

Sarcasm or joking to counter previous commenter

Direct Quoting to counter blog

Direct quoting to counter previous commenter

Rule Making to counter previous commenter

Argumentative exclamations

Exclamations to counter blog

Exclamations to counter previous commenter

Hierarchizing to counter blog

Hierarchizing to counter previous commenter

Suggesting General Hierarchies

\begin{tabular}{rr} 
Initiators & \multicolumn{2}{r}{ Comments } \\
0 & 22 \\
17 & 5 \\
8 & 2 \\
0 & 21 \\
0 & 3 \\
0 & 10 \\
12 & 5 \\
1 & 55 \\
3 & 0 \\
0 & 27 \\
0 & 0 \\
0 & 0 \\
10 & 0 \\
1 & 7 \\
0 & 0 \\
4 & 43 \\
0 & 0
\end{tabular}

The networking category, which was identified in the techcrunch.com data, but not present in the treehugger.com data, was incorporated into the discourse-promoting category (Table 13). The networking comments did not specifically operate to promote or decrease the standing of any blog users within the thread, and worked to encourage discursive connections between users, and therefore were seen to operate as discourse-promoting, rather than normalizing, comments. 
Table 13

Totals for Discourse-Promoting Category from

Techcrunch.com

Discourse-Promoting Comments

Questioning

Questioning a claim or concept presented in the thread

General Questioning

Stating Opinion

Stating an opinion

Suggesting a middle-ground solution

Providing Information

Providing additional information

Citing personal experience

Correcting

Answering

Citing sources

Plugging

Plugging a product

Plugging a blog

Apologizing

Reasoning

Salutations

Signing a post

Greeting a commenter

Exchanging pleasantries

Networking
Initiators Comments

10

22

20

6

136

211

0

6

44

209

49

42

71

33

14

6

1

0

0

0

6

11

2

As with the categories from treehugger.com, the gratifying and punishing categories were merged under the broader normalizing category (Table 14). Totals for the codes in both the normalizing and discourse-promoting categories were taken, and converted into percentages of the total number of codes identified in the techcrunch.com data to account for the numerical discrepancies in codes between the treehugger.com and techcrunch.com data sets. 
Table 14

Normalizing and Discourse-Promoting Category Totals

from Treehugger.com

Normalizing

Gratifying

Punishing

Total

Percentage

Discourse-Promoting

Questioning

Stating Opinion

Providing Information

Plugging

Apologizing

Reasoning

Salutations

Networking

Total

Percentage

$\begin{array}{rr}\text { Initiators } & \text { Comments } \\ 29 & 99 \\ 56 & 200 \\ & \\ 85 & 299 \\ 23.55 \% & 31.91 \%\end{array}$

26

217

369

7

0

0

17

2

276

638

$76.45 \%$

$68.09 \%$

The final results from the techcrunch.com data showed that discourse-promoting interactive comments occurred more frequently within the comment threads than normalizing interactive comments by a margin of 36.18 percentage points. Discourse-promoting initiator comments were also more numerous, beating out their normalizing counterparts by a margin of 52.9 percentage points. When compared to the final treehugger.com data, techcrunch.com interactive comments had an occurrence rate that was 7.48 percentage points higher than the interactive comments in the treehugger.com data. The initiator comments from techcrunch.com also had a higher occurrence rate, by 2.72 percentage points, than similar comments from treehugger.com. 
Table 15

Combined Totals for Normalizing and Discourse-Promoting

Categories from Treehugger.com and Techcrunch.com

Normalizing

Gratifying

Punishing

Total

Percentage

\section{Discourse-Promoting}

Questioning

Stating Opinion

Providing Information

Plugging

Apologizing

Reasoning

Salutations

Networking

Total

Percentage

$\begin{array}{rr}\text { Initiators } & \text { Comments } \\ 83 & 260 \\ 139 & 475 \\ & \\ 222 & 735 \\ 24.37 \% & 33.33 \%\end{array}$

74

402

893

14

1

12

27

2

1470

$66.67 \%$

\section{Discussion}

The purpose of this study was to gain an understanding of how comments either

promoted or inhibited the development of a radicalized public sphere. Dahlberg (2007) suggests that in order for a radicalized public sphere to function, discursive radicalism, which can be considered the constant challenging of information, and inter-discursive contestation, the constant shifting of discursive dominance, must function together to challenge concepts presented in the realm of public sphere discourse. The inhibitor to the development of discursive radicalism is the dominance of normalizing discourses within a community. Normalizing forces, outlined by Foucault (1974) as a system of gratifications and designed to hierarchize individuals 
based on their conformity to the dominant ideologies of a group, work to inhibit contestation, and therefore counter the function of discursive radicalism by establishing one set of truths, or norms, and rejecting all other claims as outside of the true. Normalizing discourses, however, are a necessary component of inter-discursive contestation. In order to shift dominance of a discursive sphere from one group to another, the dominating group must assert their norms and rules over the group they are supplanting. Some normativity, therefore, is necessary within discourses in order to develop a radicalized public sphere.

\section{Discursive Radicalism}

The data from both the treehugger.com and techcrunch.com comment threads observed for this study suggest, foremost, that the dominant discursive strategies within the comment threads operate to promote discourses and encourage discursive radicalism. The treehugger.com data showed that 64.35 percent of the data coded worked to promote discourse within the online community. The techcrunch.com data had a 68.09 percent rate of occurrence for discoursepromoting data within its comment threads. This numerical data suggests the dominance of discourse-promoting comments in the comment threads from both blog sites.

The diversity of the comment types that worked to promote discourse within the blog communities is also an important factor when considering the data from this study. The discourse-promoting category included a large number of sub-categories, including some, specifically the "stating opinion" and "providing information" categories, that incorporated common rhetorical strategies used in everyday speech or writing, and therefore represented a large portion of the codes identified in the study. The codes for the "providing information" subcategory, for example, accounted for 42.85 percent of the total number of codes identified on treehugger.com, and 39.38 percent of the codes from techcrunch.com. In both cases, this sub- 
category represented a larger portion of the identified codes on either blog than the total for the normalizing category on their respective sites. The codes for the "stating opinion" sub-category accounted for another 15.13 percent of the data from treehugger.com, and 23.16 percent of the codes from techcrunch.com. Combined with the totals from "providing information", these two sub-categories represent 57.89 percent of the codes, and 90.1 percent of the data in the discoursepromoting category, on treehugger.com, and 62.54 percent of the codes, and 91.84 percent of their category, on techcrunch.com.

The high percentage of comments in the "stating opinion" and "providing information" sub-categories may indicate that these categories are oversimplified and do not accurately define the codes within them. However, the significance of these sub-categories lies in their relevance to common discourse, and in the diverse way in which they may be employed by commenters. Because the "providing information" sub-category contains its own sub-categories of citing personal experience, correcting, answering, citing sources, in addition to providing information, its manifestations span a broader scope than most other sub-categories. Comments that fall within the sub-category of providing information, then, can be presented in many varying ways. For example, treehugger.com user Kcoe, in reply to a blog post announcing the discovery of a new bee, states, "The picture is not of a sweat bee, but probably a hoover fly. Note the large eyes, short antenna, and shape of the abdomen." This response accounts for two types of information providing. The first sentence falls into the sub-category correcting, for its function to correct the information, in this case the labeling of a picture, on the blog. The second sentence works to provide additional information to support the user's claim against the blog site. Lengthier comments may incorporate more information providing strategies. User Dave on treehugger.com writes: 
That's actually a common misconception in most states, actually. I checked out Michigan's bike laws (http://bit.ly/dlSgCe), which do say you have to "ride as close as practicable to the right-hand curb or edge of the roadway" EXCEPT for a few circumstances, one of which is when doing so would be unsafe "including but not limited to [situations where] the lane is too narrow to permit a vehicle to safely overtake and pass a bicycle." So, if the lane's wide enough for them to pass, ride right, but if it's not, take the lane. It's what you'll naturally wind up doing when you're riding in the road anyway.

In this comment, four different sub-categories from providing information are present. The first sentence operates to correct the previous commenter. The second was counted under citing sources because of the inclusion of a link, and the distinction between citing a source and direct quoting developed during the coding process. Direct quoting involved quoting a previous commenter or an excerpt from the blog to discuss a specific point in detail. Citing a source was defined as providing a link or citation for an external source of information. The third sentence was coded as providing information, because it functioned to reiterate and simplify information presented in a quote in the previous sentence. The final sentence was coded as citing personal experience. Although Dave does not explicitly state that it is his personal experience that bike riders gravitate toward the center of a lane while riding, his use of the term "naturally" implies that it is in his nature, and in others, to practice this riding strategy.

The number of comments that incorporated some sort of information providing greatly affected the percentage of codes included in the discourse-promoting category. This does not, however, suggest that the data is unfairly skewed in favor of discourse-promoting comments. The presence of other comment types, especially normalizing comments, suggests that users were capable of employing other rhetorical strategies into their comments. The dominance of information providing comments, rather, suggests that most commenters in the observed threads are actively trying to add to the conversation and inform other users, which is a critical function in challenging oppositional discourses and promoting discursive radicalism. 


\section{Inter-Discursive Contestation}

The development of discursive radicalism within the comment threads, however, is only one of the necessary components for the formation of a radicalized public sphere. Interdiscursive radicalism must also be shown to operate within the comment threads, which is where the presence of normalizing comments within the discourse becomes critical. While there is no set portion of normalizing that needs to occur to suggest that inter-discursive radicalism is functioning, norm-enforcing comments must be present. The apparent secondary position of normalizing discourses in the data from treehugger.com and techcrunch.com suggests, however, that normalizing comments are occurring within the blog discourses. At 35.65 percent of the data for treehugger.com and 31.91 percent of the data for techcrunch.com, however, neither site is being dominated by normalizing discourses, and it is possible for discursive radicalism to function without challenges to the concepts in the discourse being limited or discredited by one dominant group or ideology.

The diversity of ways in which normalizing comments were developed on the comment threads also suggests that individuals and groups are working to challenge each other in the fashion of inter-discursive radicalism, rather than to support one hegemonic concept. The following conversation among techcrunch.com users illustrates how normalizing discourses develop in comment threads:

Siddharth Goyal: Well Greenpeace may have some very valid points bit it seems facebook has become the favourite punching bag of all sundry. Guess people are simply jealous of somebody getting so successful in such a short span of time!

Phil L, in reply to Siddharth Goyal: I disagree. Nobody faulted Google as they grew to something far larger than Facebook will ever be. No, the problem is that Facebook proudly exhibits the personality of its founder, which is to say, an $\mathrm{a}^{* *}$ hole. 
Jeremie C., in reply to Phil L: Nobody faulted Google? Dude, what planet are you from? I don't like him much, but I do empathize with Zuckerberg. He was a student and then became a very, very powerful man, so yeah I do disagree with things he says or does but then I ask myself what I would do if I was as powerful as he is and then I think he's a decent guy :)

The comment from Siddharth Goyal was coded separately as an initiator comment, but includes two statements of opinion from the user. The comment from Phil L begins with a simple statement of disagreement. Statements like these, while similar to statements of opinion, which were included in the discourse-promoting category, work to establish, sometimes in the most minor way, a hierarchy of rightness. Phil L could have simply stated an opinion counter to the statements Siddharth Goyal made, but he instead chose to state his disagreement with the other user. This suggests that Phil L regards Siddharth Goyal's opinion as less correct than his, and believes that his judgment of Siddharth Goyal's claim is of importance to other users. Phil L's second sentence works as an information providing code, although the context of disagreement is imbedded in his word choice. The final sentence in the comment was coded as a criticism, intended to counter the previous commenter. The language use, although edited, also suggested a discrediting code for the sentence, but the overall tone of criticism led to the final decision on the coding. Both of the normalizing codes identified in Phil L's comment were categorized as punishing, given their intent to discredit and lower the standing of Siddharth Goyal's claims. Jeremie C's reply to Phil L. began with two rhetorical questions intended to counter Phil L's claims. Both of these were counted as punishing, normalizing comments. The subsequent sentences represent sub-categories in the discourse-promoting category.

Each of these examples represents a more developed sample of a normalizing comment. While there were plenty of insulting, sarcastic, discrediting comments, which are somewhat expected among internet communications, many commenters that resorted to using normalizing 
language incorporated sentences that were identified as discourse-promoting into their comments as a way to add value to their perspective and explain their opinion while still challenging others. The use of discourse-promoting strategies in normalizing comments may also indicate that users, rather than simply working to uphold any dominant ideals of a discursive sphere, are relying on rhetorical strategies to create compelling arguments to challenge other opinions and gain dominance within a sphere.

\section{Conclusion}

From this study, a basic framework for how norms and discourses operate in blogs to limit or enhance the radicalized public sphere is developed. Radicalized public sphere discourses are essential in working against the power traditionally held by the mass media to shape public opinion and subdue oppositional points of view (Gamson, Croteau, Hoynes \& Sasson, 1992; Noelle-Neumann, 1977; Scheufele, 1999). Researchers have proposed that the Internet and blogs in particular are the ideal locale for new, mainstream-resistant spheres of public opinion (AlSaggaf, 2006; Beers, 2006, Dahlberg, 2007). However, to date there has been little evidence to support those claims. The findings of this study suggest that discursive radicalism and interdiscursive contestation, the building blocks for a radicalized public sphere, are operating on the comment threads of the observed blogs. Furthermore, it suggests that normalizing discourses operate as a secondary form of commenting on the blogs in this study, and that discoursepromoting comments dominate these discursive spaces.

The data, overall, suggests that discursive radicalism and inter-discursive contestation are functioning together on both treehugger.com and techcrunch.com to promote radicalized public sphere discourses in these online spaces. Normalizing comments, while present, are not dominant enough in the discourse to allow any one group or ideology to gain dominance over the 
discursive space, and are therefore not inhibiting discourse on these blog sites. This study provides evidence to support Dahlberg's (2007) claim that a radicalized public sphere can operate in the online space of a blog, but further suggests that, rather than occurring in the text of a blog itself, the radicalized public sphere is developed within the discursive space of a blog's comment threads.

While this study provides compelling evidence to support claims of successful radicalized public spheres on treehugger.com and techcrunch.com, the data is not generalizable to the state of commenting on blogs as a whole. Additional studies of different blogs, and more in-depth studies into the nature and development of comment threads on blogs are necessary to enhance the understanding of how discourses are developed on separate sites, and in different discursive spheres. Potential studies could work to compare comment threads from blogs that are hosted on separate sites, but which share similar general purposes and produce content for the same discursive sphere - multiple technology blogs, for example. Additional studies are also necessary on the mainstream news blogs, both those exclusively hosted online and those created by newspaper companies, to gain a better understanding of the difference between comment threads that develop on smaller blogs with a limited discursive sphere, and comment threads that attract the attention of and are open to the general public.

Further investigation is also necessary to better understand why the radicalized public sphere develops in some comment threads and blog sites, but not others. Investigation into where these types of discourses develop may shed further light on how they operate and how to improve online discourses, so that they may better incorporate radicalized public sphere discourses. The scope of this project is a major limiting factor, and future studies on a broader 
selection of blog posts, from multiple blog sites, may provide richer data and further understanding into the operation of an online radicalized public sphere. 


\section{References}

Al-Saggaf, Y. (2006). The online public sphere in the arab world: The war in Iraq and the Al Arabiya website. Journal of Computer-Mediated Communication, 12, 311-334.

Barlow, A. (2008). Blogging America. Westport, CT: Praeger.

Beers, D. (2006). The public sphere and online, independent journalism. Canadian Journal of Education, 29, 109 - 130.

Cammaerts, B. (2008). Critiques on the participatory potentials of web 2.0. Communication, Culture \& Critique. p. 358-377.

Carroli, L. (1997). Virtual encounters: Community or collaboration on the internet? Leonardo, 30, 359-363.

Collingwood, P. (2007). Recent public sphere theory as an evaluative resource. Journal of Community, Citizen's \& Third Sector Media \& Communication, 3, 15-24.

Corbin, J. Strauss, A. (1990). Grounded theory research: Procedures, canons, and evaluative criteria. Qualitative Sociology. 13, 1, 3-21.

Dahlberg, L. (2007). The Internet, deliberative democracy, and power: Radicalizing the public sphere. International Journal of Media and Cultural Politics, 3, 47-64.

Dean, J. (2001). Cybersalons and civil society: Rethinking the public sphere in transnational technoculture. Public Culture, 13, 243-265.

Farrell, H. Drezner, D. (2008). The power and politics of blogs. Public Choice, 134, 15-30.

Festinger, Leon; Riecken, Henry W.; Schachter, Stanley, (1956). When prophecy fails: A Social and Psychological Study of A Modern Group that Predicted the Destruction of the World. Minneapolis, MN, US: University of Minnesota Press.

Foss, S. K. (2004). Rhetorical criticism. Long Grove, IL. Waveland Press.

Foucault, M. (1975). Discipline and Punish: The Birth of the Prison. New York, NY: Vintage Books.

Gamson, W. A. Croteau, D. Hoynes, W. Sasson, T. (1992). Media images and the social construction of reality. Annual Review of Sociology, 18, 373-393.

Glaser, B. G. The constant comparative method of qualitative analysis. Social Problems, 12 (4). p. $436-445$. 
Gripsrud, J. (2009). Digitising the public sphere: Two key issues. Javnost - The Public, 16(1), 516.

Habermas, J. (1974). The public sphere: An encyclopedia article. New German Critique, 1, 4955.

Habermas, J. (1991). The structural transformation of the public sphere. (T. Burger \& F. Lawrence, Trans.). Massachusetts Institute of Technology: MIT Press. (Original work published 1962).

Mann, C. Stewart, F. (2000). Internet communication and qualitative research: A handbook for researching online. London: Sage.

Maratea, R. (2008). The e-rise and fall of social problems: The blogosphere as a public arena. Social Problems, 55, 1. 139-159.

McCombs, M. E. Shaw, D. L. (1972). The agenda-setting function of mass media. Public Opinion Quarterly, 36, 2. 176-187.

McGee, M. C. (1980). The "ideograph": A link between rhetoric and ideology. The Quarterly Journal of Speech. 66, 1. 1-16.

Nardi, B. A. Schiano, D. J. Gumbrecht, M. Swarts, L. (2004). Why we blog. Communications of the ACM. 47, 12. p. 41-46.

Noelle-Neumann, E. (1977). Turbulences in the climate of opinion: Methodological applications of the spiral of silence theory. The Public Opinion Quarterly. 41, 2. 143-158.

Robinson, S. (2006). The mission of the j-blog: Recapturing journalistic authority online. Journalism, 7, 65-83.

Rushing, J. H. Frentz, T. S. (1991) Integrating ideology and archetype in rhetorical criticism. The Quarterly Journal of Speech, 77, 1, 385-406.

Scheufele, D. A. (1999). Framing as a theory of media effects. Journal of Communication, 49, 1, 103-122.

Scheufele, D. A, Tewksbury, D. (2007) Framing, agenda setting, and priming: The evolution of three media effects models. Journal of Communication, 57, 9-20.

Selber, S., Johnson-Eilola, J. (1996). Policing ourselves: Defining the boundaries of appropriate discussion in online forums. Computers and Composition, 13, 169-291.

Strauss, A. Corbin, J. (1990). "Basics of Qualitative Research Techniques and Procedures for Developing Grouned Theory". Second Edition. 
Trenz, H. (2009). Digital media and the return of the representative public sphere. Javnost - The Public, 16(1), 33-46.

Wander, P. Jekins, S. (1972). Rhetoric, society, and the critical response. The Quarterly Journal of Speech, 441-450.

Witschge, T. (2008). Examining online public discourse in context: A mixed method approach. Javnost - The Public, 15, 2. p. 75-92. 


\section{Appendix}

Definitions and examples of major sub-categories of data.

Agreeing: Stating one's agreement with another user, the blog author, or a topic in the blog. Liam Casey I agree with this completely.

Apologizing: Making a statement to express regret or ask forgiveness for previous behavior in the discourse.

Sami Grover Sorry Adam - I certainly didn't mean to misrepresent your views. Just using it as a start point for a conversation.

Criticizing: Pointing out faults or expressing one's personal judgments of a topic, person, or issue related to the discourse.

Ughh your an imbusul. He is quite clever. I bet you have never even attempted to create something, on your own, without being told to. You fucking sheep.

Direct quoting: Copying text from the blog or another comment into one's own comment to discuss it in detail.

Guest "its about choosing what you care about supporting." Yes I know. That's why I choose conventional over organic.

Disagreeing: Stating one's disagreement with another user, the blog author, or a topic in the blog. Phil L I disagree. Nobody faulted Google as they grew to something far larger than Facebook will ever be.

Discourse-promoting: Any comment that encourages discursive radicalism by questioning or providing information to supplement the discourse.

Evad Flor There is enough cork trees in the globe to sustainably supply the wine industry for over 100 years. The used of plastic and screw caps will decrease the demand for cork and in time the cork forests will be cut own and new crops such as fast growing eucalyptus will planted for the paper pulp industry. The cork forest ecosystem will be forever changed. The products above and the products we make at corkologie.com are made from the waste stream from the wine industry. Not using cork as a wine closure will not only shrink this waste stream, but will destroy the forest eco-system that has existed with man since roman times. Just as a side note Cork is used in many things that you would never think about, such as, the core of every MBL baseball that it pitched and hit out of the park.

Exclamations: Statements of excitement of disbelief, often brief. J_sparings LOL

Gratifying: Any comment intended to promote the perceived value of an opinion, ideology, or statement from one user over another.

dany I agree $100 \%$.Also, It kills me that people forget that $\mathrm{Co} 2$ is essiential for life on this planet. 
Hierarchizing: Ranking one comment or concept above or below another.

Rdx Oh well, excuse my grammar, I scored 720/800 on my GRE btw :P

Milke Which means what? You are only ignorant when you have to say something yourself, but by gosh you can fill in bubbles?

Networking: Comments made to form connections, especially those beneficial to the user, with other commenters.

Mark, working on hubski.com Hey Alexis. Is there a Reddit meet up event planned? We did submit Gokode to YC. If your offer stands and you can give me a few minutes at the Rally, I would love the chance to elevator pitch it to you.

Normalizing: Any comment that promotes a norm, whether mainstream or counter public, by gratifying or punishing a user.

Rocky fisher is an idiot You are nuts, lets just lock our kids up in padded rooms for fuck sake. Just ridiculously stupid.

Plugging: Promoting a specific product with the intent to the draw attention of blog users to it. ecoTransitions If you are serious about saving water, want a toilet that really works and is affordable, I would highly recommend a Caroma Dual Flush toilet. Caroma toilets offer a patented dual flush technology consisting of a 0.8 Gal flush for liquid waste and a 1.6 Gal flush for solids. Caroma, an Australian company set the standard by giving the world its first successful two button dual flush system in the nineteen eighties and has since perfected the technology. Also, with a full 3.5 " trap way, these toilets virtually never clog. All of Caroma's toilets are on the list of WaterSense labeled HET's epa.gov/watersense/pp/find_het.htm and also qualify for several rebate programs currently available throughout the US as well as LEED points. Please go to http:/ecoTransitions.com/howto.asp to see how we flush a potato with the half flush (0.8 gallons), meant for liquid waste. To learn more about toilets you can also visit my blog http://pottygirl.wordpress.com/.

Providing information: Supplying additional knowledge, either personal or from an outside source, to supplement the discourse.

DaveInCalif Just checked the Apple Store. The new Nano is 8GB and 16GB, the same as the old one (and the one before that).

Punishing: Any comment intended to decrease the perceived value of an opinion, ideology, or statement from one user over another.

Uncle_Ben wow. your ignorance is alarming and its clear you are missing the entire point of choosing to eat something that is organic.

Questioning: Asking a question to clarify an issue or point out an issue or flaw in the discourse.

Jason Berberich So, can the new Nano play video? Steve only showed and mentioned audio and photos, and the menus didn't seem to have a video icon. 
Reasoning: Using logic to develop or supplement a statement in the discourse.

Insurged What dolphin species are being hunted? are they endangered? is the 20 000 individuals allowed to be hunted putting the specie at risk? I know dolphins are cute, but these are the questions you must ask yourselves before saying that a [practice] is barbaric or outrageous [and] unacceptable.

Rhetorical questions: Questions asked by a user as a rhetorical tool to support or contest another user rather and seek an answer.

Vic Did I read that well, "6,000\$ per founder"? What is that for, for buying toilet paper? And they take $6 \%$ of your company? Excuse me but this is laughable.

Rule-making: Suggesting a set of regulations that should be applied to a topic in the discourse.

Brspaworks GOD said we can eat anything that swims in the ocean, and anything that flies in the air. case closed

Salutations: Any greetings directed toward blog users. This sub-category also includes exchanges or pleasantries between users, and instances of users signing their posts.

April Streeter Hi, Damon: Even though any bike whizzing by me on the pavement would be disconcerting if not irritating, and especially in the situation you describe, I would think that it's a failure of training for the kid involved - they are going too fast to stop - than a complete support for the "never ride on the sidewalk" theory

Sarcasm: Comments that, from the context and language of the rest of the comment, present a statement that has the opposite meaning of the author's opinion with the intent to mock or devalue another comment.

TheBone I'm sure YOUR work has soooooo much more to say. Fuckin' putz.

Scorekeeping: A short comment, often only one or two words, that assigns points or values to other comments.

Kmiller +1

Sloganing: A catchy phrase that makes a general demand on an issue.

Falconsbeetpackers [...] smoke weed er day

Stating opinion: Expressing one's personal belief about an issue presented in the discourse.

Dave, A right-wing investor, collector, wrestling fan, and Buddhist. I just want less cars on the road, period.

Thanking/Complimenting: Expressing gratitude or admiration for another user.

grace SickToMyStomach: your phrasing is awesome! lol seriously you sound like something out of a book, "death by a 1000 cuts is still death." really i just liked your overall post and i hope other people like orngcrush see it and can figure out where their thinking went the wrong direction. 